\title{
COLLABORATIVE GOVERNANCE IN PROPELLING THE TRANSMISSION PROCESS OF RESEARCH RESULTS INTO INDUSTRIAL PRODUCTS AND ITS DEVELOPMENT AT THE MINISTRY OF RESEARCH, TECHNOLOGY, AND HIGHER EDUCATION (THE DEVELOPMENTAL STUDY ON ZENMED'S ORTHOPEDIC IMPLANT)
}

\author{
Dwi Lestari \\ Department of Administrative Science, \\ Faculty of Administrative Science, \\ University of Indonesia, \\ Jakarta, Indonesia, \\ dwieternity@gmail.com
}

\author{
Lina Miftahul Jannah \\ Department of Administrative Science, \\ Faculty of Administrative Science, \\ University of Indonesia, \\ Jakarta, Indonesia, \\ linamjannah@yahoo.com
}

\begin{abstract}
The transmission process of research results into industrial products is a step forward to utilize research results and development for the industry and the people. To achieve this, collaboration must be done by the involved stakeholders, which are the academics, business and the government. This thesis contributed to the understanding of how collaborative governance can propel the transmission process of research results and the development in the Ministry of Research, Technology, and Higher Education and to understand the collaboration pattern between stakeholders in propelling the transmission process of research results and the development using the collaborative governance concept.

This study used qualitative method with post-positivism approach, also data collection with in-depth interview. The result shows that by collaborating with stakeholders, the process of transmission of research results into industrial products can be propelled. In the case of the cooperation pattern in research and development, the researcher has to pay attention not only in the scientific field but also the needs of the people and the market. The reason is that by considering the people's needs, the innovation will be treated well by the industry.
\end{abstract}

Keywords : collaborative governance, collaboration, triple helix

1. Preface

Indonesia has been undergoing
prominent drawbacks in its global competitiveness in the last two years, which is observable on the report of The Global Competitiveness Index that depicts the ranks of the competition between many countries in the world. In 2015, Indonesia occupied the $37^{\text {th }}$ position out of 140 countries which later shifted in regress in 2016 by the $41^{\text {st }}$ position out of 138 countries. Such below-average fundamental stake amongst East Asian and Pacific countries deems of more concern, many of which cover the Technology Readiness Level (TRL) and the extent of primary education and health that contribute as incentives to the efficiency-driven development. This stake in the field of technology, as a matter of fact, is also interrelated with every innovation that remains substandard or inadequate. For that matter, it is pivotal to establish a policy that can help increase Indonesia's power of competitiveness against other East Asian and Pacific countries.

In today's practice, research results and innovation often end up merely in university libraries or the Ministry or Institution's annual report. It is known that there is a gap or interlude that dissociates the invention obtained from types of research in universities/institutions from the innovation that introduces technology to new opportunities in businesses through the commercialization of the invention itself. Such gap in a more common term is entitled as the phenomenon of Valley of Death (which in literature is also termed as Darwinian Sea), defining a condition where the compatibility of investment and the financing process before invention becomes a radical, technology-based innovation that confronts the 
highest risks out of complexity and uncertainty. This gap exists in the midst of research results that are conducted based on the requirement for the industry, making it impossible for many of the research to reach a higher TRL within the phase of applied research innovation.

One of the issues that the agency of research and development has been facing along the way is of the inapplicability of the research results of the people and industry, in which a missing link occurs between many of the research and the users, who either come from the government or the private industry. There is also an issue of overlapping actions on the institutional side. Other than issues related to quality and quantity, types of research that were done by various agencies in Indonesia often go through an overlap. Consequently, the study fails to generate any significant progress as a result of reiterating other agencies' works. Moreover, there is also a predicament apropos of the poor interagency coordination. Minister of Research, Technology and Higher Education of the Republic of Indonesia asserted that the industry could grow in optimality through the use of technology. However, there is still a problemin the process of transmitting research results into industrial products (the practice among the community). Many of such research in college, local government, and the world industry have not been integrated, causing the incapability of the industry to capture the research results and the innovation in technology. (Suara Merdeka, November 29, 2016). One more problem involving the agency of research and development is the huge amount of its research activities (LPNK/KL/PT) that are limitedly relevant to the alpha testing (expansion of the prototypes, replica, and the laboratory test) and beta testing (field test and further development), which have not yet to come to the diffusion of innovation.

To overcome such problems, a policy to propel the process of transmitting research results to the industry is necessary. Developed countries have proven through many experiencesthat the incorporation of Science and Technology into the economic activity has brought remarkable welfare-both economically and socially-for the nation.
According to Presidential Regulation No. 13 of 2015 pertaining to Ministry of Research, Technology, and Higher Education that modifies the nomenclature and combines Ministry of Research and Technology with the Directorate General of Higher Education that provides the opportunity for the enhancement of coordination and collaboration between the agency of research, the non-ministerial government departments, and colleges all over Indonesia. This coordination is expected to bring forth useful and competitive forms of research that will attract industrial investors to invest in the Research \& Development (R\&D) in Indonesia.

In both direct and indirect approaches, the awareness of the significance of interaction and communication between innovators has grown for a long time, for instance, in the forms of notion and conception 'Triple Helix A-B-G', which is designed to motivate academicians, business people, and the government to participate in a cooperation in constructing innovation system. Nevertheless, in today's reality, the communication and interaction between these innovators have shown neither intensive improvement nor productivity. A call for contribution, facilitation, and the intensive system being offered by the government seemingly remain ineffective.

In the direction of transmitting the research results for the industry, a synchronization and a collaboration of strategic, integrated policies are prominent amidst the stakeholders through a collaborative governance. Ansell and Gash (Ansell \& Gash, 2008) describe collaborative governance as " $a$ governing arrangement where one or more public agencies directly engage non-state stakeholders in a collective decision-making process that is formal, consensus-oriented, and deliberative and that aims to make or implement public policy or manage public programs or assets." Such definition emphasizes the cooperation between the governmental and nongovernmental instruments to achieve a common goal built upon a consensus to meet the public interest.

The collaboration between stakeholders as stated by Wanna \& O'Flynn (Wanna \& 
O'Flynn, 2008) functions to intensify the practice and effectivity of public administration on the whole so that the objective of the collaboration can be attained promptly. Commitment to the collaboration can create an organizational shift and affect the allocation of resources since it allows shared resources along with shared responsibilities. The collaboration can also combine expertise and capacity to produce collective learning and shared experiences that eventually will create a construction of institutional capacity from inside and outside the organization.

One of the developing kinds of studies leading up to such transmission processtothe industry is the utilization of biomaterial technology to manufacture orthopedic implant in collaboration between Agency for the Assessment and Application of Technology (BPPT), PT. Zenit Allmart Precissindo, and the Ministry of Research, Technology, and Higher Education by launching a prototypical implant product SS316L on February 20, 2017. The result makes up one of the success stories of a program called Intensive Innovation and Technology employed in the industry, Directorate General of Innovation Strengthening at the Ministry of Research, Technology, and Higher Education since this research is considerably implementable in the industrial mass production. Furthermore, this research depicts one of the favorable outcomes of collaboration between several elements in innovation $\mathrm{ABG}$, in which the $\mathrm{A}$ stands for Academic of BPPT, B for Business represented by PT. Zenith Allamart Preccisindo, as well as $\mathrm{G}$ for Government that is the Ministry of Research, Technology, and Higher Education to transmit and push the research results of orthopedic implant towards the industry.

Based on the background study elaborated in the discussion above, the research questions that aim for answers are as follows:

1. How can collaborative governance assist in improving the transmission process of the research results at the Ministry of Research, Technology, and Higher Education?

2. How does the collaboration between stakeholders come in the form of as a means to improve such transmission process?

\section{Theoretical Framework}

\subsection{Concept of Innovation}

One of the innovations proposed by OECD addresses that Product innovation: goods or services that are new or significantly improved. This includes significant improvements in technical specifications, components, and materials, incorporated software, user-friendliness or other functional characteristics. Therefore, what is meant by product innovation is a product that encompasses significantly upgraded goods or services through the means of science and technology. The improvement can be technical specifications, materials and components, software, user-friendly aspect, and functional characteristics as well.

\subsection{Concept of Collaborative Governance}

John Wanna (Wanna \& O'Flynn, 2008) propounds that the idea of collaboration is equal to working together or cooperating with other people, which implies that an individual or a doer together with groups or organizations strives to work under various terms and conditions. The term 'collaboration' began to spread in the nineteenth century-specifically in the period of industrial revolution where more complex organization made an appearance and the division of work increased. Collaboration is the fundamental norm of utilitarianism, social liberalism, and collectivism-all of which correspond to one another, then, the scientific management and the theory of public relations. Ansell and Gash (Ansell \& Gash, 2008) put forward the definition of collaborative governance, which is "a governing arrangement where one or more public agencies directly engage non-state stakeholders in a collective decision-making process that is formal, consensus-oriented, and deliberative and that aims to make or implement public policy or manage public programs or assets."

Excerpted from Wildavsky (1973), collaboration and coordination embody several distinct dimensions. First, collaboration can incorporate cooperation to build a sense of togetherness, increase consistency, and adjust 
each action between doers. Second, collaboration can serve as a process of negotiation, which includes the readiness to compromise or to trade off. Third, collaboration can also involve the importance of surveillance, examination, and active coordination. Fourth, collaboration can include power and enforcement, the leverage to constrain to definite results or our desires, up to certain boundaries of others' obedience and involvement. Fifth, collaboration can involve commitment and future intentions, prospective behavior, planning or preparation to harmonize any actions. Lastly, a collaboration including involvement, the development of internal motivation and personal commitment for any projects, decisions, the purposes of organization or strategic goals. Ansell \& Gash, additionally, depict the model used in collaborative governance as illustrated as follows:

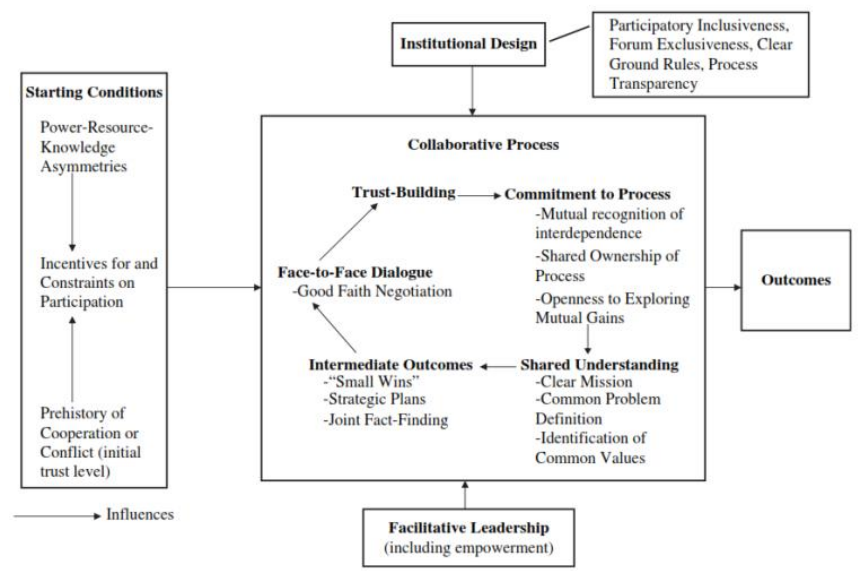

Figure 1.1 Model Collaborative Governance. Source: (Ansell \& Gash, 2008)

As in the collaborative governance itself, there are primary variables such as:

1.1. Starting Condition, a current condition that cansimultaneously promote and hinder the cooperation between stakeholders - or the one between agencies and stakeholders. Such critical condition consists of three main variables, namely:

a. The disproportion between resource and the capacity of different stakeholders

b. Motivation to collaborate coming from the stakeholders,

c. History of preceding collaboration and conflicts between stakeholders.
2.1. Leadership, leadership is often referred to as a critical factor that can bring success to the performed collaboration. The substantial roles of leadership cover the making of a collaboration and developing its rules, building the trust between stakeholders, accommodating dialogue or discourse, and finding mutual goals.

3.1. Institutional Design, in order to succeed in collaboration, several institutional designs need to be attained, such as the quality of inclusivity and the sense of being commitment-oriented coming from any parties.

4.1. Collaborative Process, the model of collaboration process is mostly described as a process of building one. The process of collaboration consists of several processes (Ansel \& Gash, 2008), which comprises:

a. Face to Face Dialogue, a direct discussion that is necessary for determining opportunities to achieve any mutual goals.

b. Trust Building, it is important to build trust as a part of actualizing a collaboration, especially when there is a past-time conflict encountered by each side of the collaborators that results in an uneasiness to collaborate.

c. Commitment to the process, a commitment is no other than a crucial factor of a successful collaboration. If a public agency shows a lack of commitment, particularly on the base level, then such matter will make a leading problem.

d. Shared Understanding, there ought to be a mutual understanding that the purpose of collaboration is to carry out the same goal that is often brought up as "common mission, common aims, common goals."

e. Intermediate Outcome, the success of a collaboration regarding its results is visible when a purpose serves, and the advantage of collaboration becomes concrete as a "small wins." 


\subsection{The Triple Helix Concept}

One of the forms of collaboration in the field of innovation and technology is known as the Triple Helix concept. At the end of the 1990s, Etzkowitz and Leydesdorff introduced the Triple Helix model concerning the development of innovation. In a knowledgebased economy, the creation of the knowledge base depends on the synergies created between the three main actors of the economy: academia, business, and government. Each actor can be linked to a specific element of the economy: the universities are responsible for the creation of novelty, businesses generate wealth, and the government is responsible for the governance of interactions among the actors and is the keeper of societal rules (Leydendorff, 2006). One approach to the Triple Helix accentuates that the interaction between universities (academia, including the institutions of research, development, and engineering), industry, and the government-constitutes the essential elements of the enhancement of a conducive state in innovation.

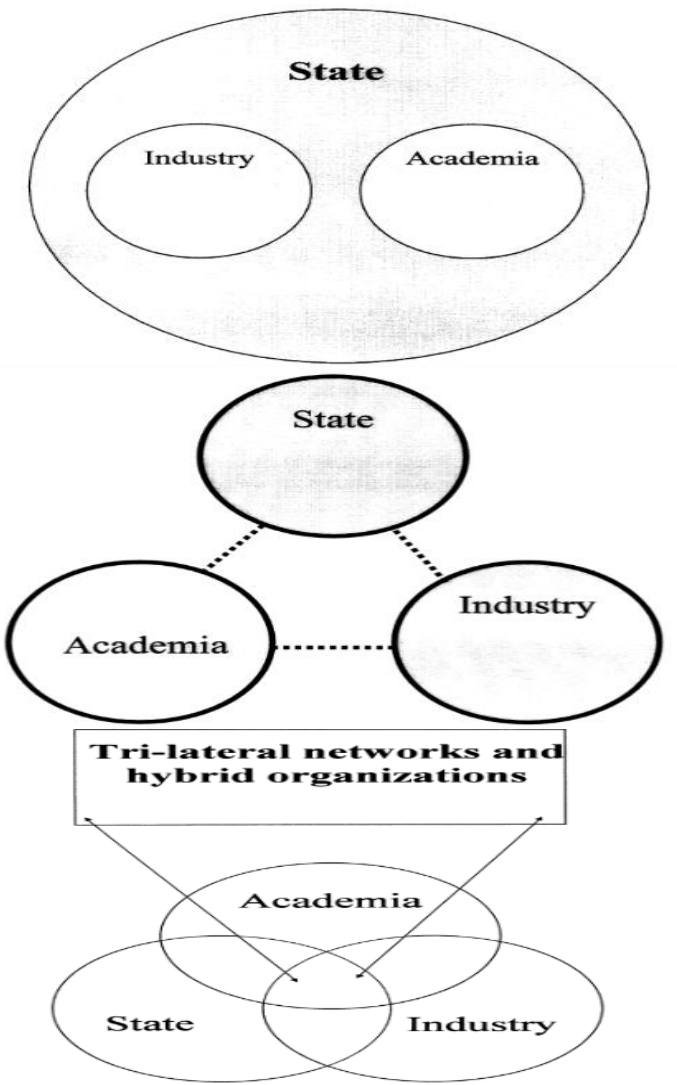

Figure 2. 2 Models of the Triple Helix

Source: (Etzkowitz \& Leydesdorff, 2000)

\subsection{Orthopedic Implant}

The bone plate is one of the components of orthopedic implant that replaces the structure and function of a biological part that works as a substitution or replacement for the bone as a support for the fracture. In order to replace the organic material of the bone, there needs to be a synthetic biomaterial that can be applicable inside the human body. Biomaterial refers to a material that comes in a direct contact with the biological system in every living thing. Such material is supposed to feature several qualifications, such as having zero harmful effects on human body, the quality of corrosionresistant, and the strength and endurance towards fatigue. The biomaterial concerning its application is used to replace and restore the functions of bone components after undergoing defect or damage. One medically applied invention in technology and biomaterial is the bone plate.

\section{Research Methods}

This research uses the post-positivist paradigm as it emphasizes on the verification of the previous theoretical frameworks, which cover the innovation theory and the collaborative governance theory. The purpose of this research is to illustrate how collaborative governance theory contributes to the transmission of a research into an eligible industrial product on Ministry of Research, Technology, and Higher Education. Moreover, this research also uses basic theory. The research is conducted through qualitative method. According to Creswell (2003) by using the qualitative method, the obtained knowledge is formed through several perspectives and ways of interpreting that come from the participants included in the research, not restricted to the conductor of the research. The collection of the data is gathered through literature studies, indepth interviews and observations in Focus Group Discussion.

Based on the concept of collaborative governance, thus the informants are divided into three groups:

1. Scholars, who are involved in this study are engineers from Agency for the Assessment and Application of 
Technology, exclusively the Material Technology Center

2. Business, PT. Zenith Allmart Precissindo which is the manufacturer of Zenmed's Bone Plate. The informant is Mr. Endi Kustamsih, the person in charge of the Bone Plate project from PT. ZAP.

3. The government, which is represented by:

a) Head of Industrial Sub-directorate of Raw Material and Advanced Material, Directorate of Innovation of Ministry of Research, Technology, and Higher Education, Dr. Hanief Arief.

b) Head of Sub-Division of Domestic Cooperation, Bureau of Cooperation and Public Communication, Ministry of Research, Technology, and Higher Education, Wike Wijayanti.

c) Staffs and functional who are related to the industry, Pratiwi, Erlani, and Yenni.

4. Focus Group Discussion, in which the researcher was involved as an observant. The informants in this FGD are:

a) Director of Medical Devices and Household Health Supplies Licensing, Ministry of Health, drg. Arianti Anaya, MKM.

b) Chief Director of Prof. Dr. R. Soeharso Orthopedic Hospital, Surakarta, Dr. dr. Pramuji Utomo $\mathrm{Sp}$. OT $(\mathrm{K})$ as the receiver of the bone plate.

c) Head of the Association of Indonesian Medical Devices Traders, Ade Tarya Hidayat.

d) Third secretary of Task ForceInnovation Technology Commercialization (TF-ITC) which is National Working Group on Technology Commercialization in Indonesia, Hendy Risdianto Wijaya.

e) Apart from the speakers above, the experts from the Ministry of Research, Technology, and Higher
Education, Faculty of Medicine of Universitas Indonesia, LIPI, and stakeholders were also invited and present.

\section{Discussion}

Based on the data acquired hence the study can be illustrated as:

1. Starting condition, the current condition which can enhance the corporation between stakeholders and between agency and stakeholders. The critical starting condition consists of three primary variables which are:

a. The disproportion between the resource and the capacity from different stakeholders, the researcher has advanced technology which is able to turn raw materials of stainless steel into a biocompatible material for the health technology. As for PT. ZAP, their excellent history in funding, manufacturing, and marketing can result in competitive price in the market. The Government through Ministry of Research, Technology, and Higher Education supports the conducive requirements for the research and its development, thus giving intensive funding for trial production, testing, and certification based on the standard from the ministry of health as the agency which conducted license for health tools.

b. Stakeholders' motivation to collaborate, based on the background and the different source materials that every agent has, collaboration is needed to enhance the goal through the speed of innovation. This act will combine knowledge and experience every agent possesses to find a solution for each problem faced. Furthermore, every agent will also share the resources (sharing resource) and the risk (sharing risk) in terms of the factor of cost efficiency, thus reducing the redundant resources that leads to cheaper and commercial products. Hence, entrepreneurship capability is necessary for the sustainability of innovation and its products in the industrial commercialization.

c. History of preceding cooperation and conflicts between each stakeholder, the history of preceding cooperation and conflict is a major factor in building up the commitment and trust between stakeholders. 
2. Leadership, leadership is often regarded as the key element for a successful collaboration. The central roles of leadership are to construct and develop the rules in collaboration, to build up the stakeholders' trust, to facilitate dialogues, and to decide the common goals. In this context, leadership means that the government has already given its support for the development of the orthopedic implant or the bone plate innovation by granting priority policy for the development of domestic-manufactured medical devices as stated in Presidential Regulation No. 6 of 2016 and Regulation of Health Minister No. 17 of 2017. Moreover, a commitment in the field of marketing between the Ministry of Health, Orthopedic hospitals, and the Government Procurement of Goods and Services Agency (LKPP) has been made to prioritize certified and authorized medical devices.

3. Collaborative Process, collaborative process is a process in constructing collaboration. According to Ansell and Gash (2008), there are five steps of the collaboration process, which are:

a. Face to Face Dialogue, a direct discussion between two parties to settle an agreement. For example, two stakeholders meet to discuss a strategy to solve problems that exist. In the case of the bone plate, there is a dismay regarding a number of bone plates used after production from the researcher and the industry involved. Therefore, Focus Group Discussion is required to assess the problem from the points of view of the research conductor (BPPT), industry, Ministry of Research, Technology, and Higher Education, Orthopedic hospitals, and the Organization of Healthcare Entrepreneurs.

b. Trust Building, trust building is substantial between the stakeholders to form, especially if there have been conflicts in the past which obstruct the process of building the trust and good faith since the beginning of the collaboration. This process is done through the making of a cooperation agreement which included the law and order for each party to respect. In addition, this process is required to avoid a dispute of proprietary and royalty distribution in the future.

c. Commitment to the Process, commitment to the process is one of the crucial indicators of a successful collaboration. If the commitment of public agency is considered as weak, particularly at the central level, it will be a grave problem for the people involved to carry on.

d. Shared Understanding, there has to be a shared understanding to ensure the goal of the collaboration is what is called "common mission", "common aims", and "common goals". The collaboration needs to have an agreed vision and mission to develop domestic medical devices with international quality with lower price.

e. Intermediate Outcome, intermediate outcome is the success of collaboration from the viewpoint of the outcome and the perspective of profit that are reached through "small wins" or the short-termed to intermediate-termed goals every year.

4. Institutional Design, institutional design is notably significant to make sure of the success of the collaboration. There are some institutional designs that must meet the requirement which stated that the parties involved in the collaboration must be inclusive and hold firmly to the commitments that have been made. The institutional design in the collaboration to develop the bone plate innovation is depicted as what follows:

a. The Reinforcement of Downstream Program from the Ministry of Research, Technology, and Higher Education is supported by the listed policies:

i. Act No. 18 of 2002 about National System of Research, Development, and Application of Science and Technology,

ii. Act No. 3 of 2004 on Industry,

iii. Government Regulation No. 20 of 2005 on Copyright and Result if the Result of Research and Development by College and Research and Development,

iv. Government Regulation No. 35 of 2007 on the Allocation Half of 
Profits of Business Entities for the Engineering, Innovation, and Diffused Technology Activities,

v. Presidential Regulation No. 7 of 2015 on State Ministry Organization,

vi. Presidential Regulation No. 13 of 2015 on Ministry of Research, Technology, and Higher Education,

vii. The Regulation of the Minister of Research, Technology, and Higher Education No. 13 of 2015 on Strategic Plan Ministry of Research, Technology, and Higher Education from 2015 to 2019; Decree of Minister of Research, Technology and Higher Education No. 341/M/Kp/V/2015 on Incentive Program utilized by Industry,

viii. Regulation of the Minister of Research, Technology, and Higher Education No.4 of 2017 on Guidelines for Cooperation at the Ministry of Research, Technology, and Higher Education

b. Budget, a budget is oftentimes dubbed as a classical problem by bureaucrats and researchers due to its constant appearance in a discussion. Apart from the small budget for research and development that is only $0.08 \%$ of the GDP, there is also an inflexibility in excising the budget. Furthermore, the strengthening of researchers and developers' role are needed to ensure the researchers' freedom in doing their studies. One of the regulations that our researchers have been complaining about is the very-detailed budget which takes more time to process.

c. Infrastructures, in terms of infrastructure these days, the Ministry of Research, Technology, and Higher Education has not yet made their database on research and development as what Research and Development and colleges are doing or have done, which becomes the obstacle for those who want to develop their research. The unavailability of a database forces the researchers to start their studies from the beginning for the data available is unorganized. Database is important because it can be a determiner for future research and an indicator of how far the research has covered which will be useful for innovations and leading industry.

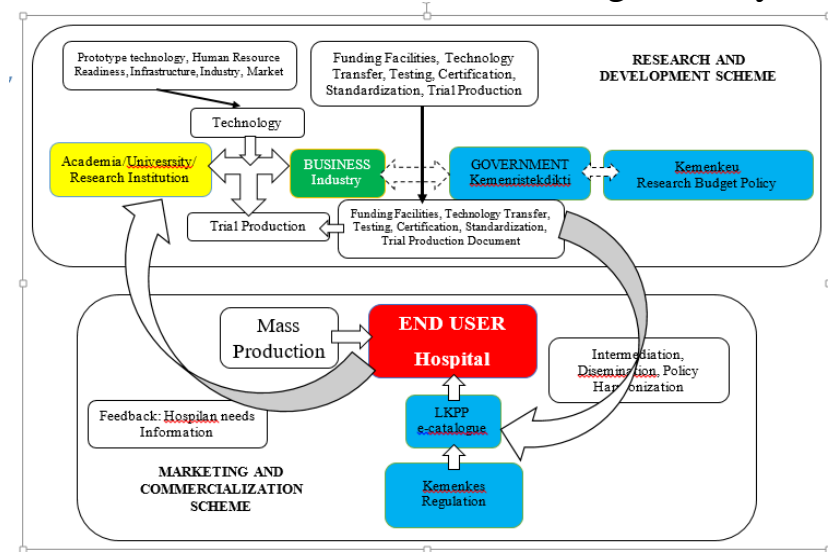

Figure 4.1. Research \& Development and Marketing \& Commercialization Scheme Bone Implan Zenmed Source: (Writer, 2017)

\section{Summary}

\subsection{Conclusion}

1. Collaborative governance is a cooperation between concerned stakeholders that has led to the success of developing existing research to be industrial products through collaboration between BPPT researchers and an industrial corporation, PT. Zenith Allmart Precisindo. Also, support in regulation and funding by Ministry of Research, Technology, and Higher Education, and also supporting regulations and from related ministry, which in this case in Ministry of Health, Surakarta Orthopedic Hospital, and LKPP.

2. Researchers need to pay attention to the pattern of the cooperation in doing the research and development for it is not merely for the sake of the subject of the research, but also its contribution to the people. If the researchers adjust the products to meet the mass' needs and desire, the industry will exercise the research to become a product worth selling. The researchers not only have to base their research on technology-driven factor, but also have to consider the market-driven factor. 


\subsection{Recommendations}

Based on the result of the conducted study, the researcher would like to give some recommendations:

1. For the Government

a. Ministry of Research, Technology, and Higher Education needs to strengthen the policy to enhance the transmission process of a research into an industrial product by organizing cooperation scheme between the researchers and the related industry. By doing so, the research and the development that is done by the agency of research and development and colleges will have a contribution to both the academics and the nation based on market-driven technology innovation. The Ministry of Research, Technology, and Higher Education is advised to conduct research and make an accurate roadmap of people' needs which will be the main reference for future research.

b. Ministry of Research, Technology, and Higher Education is also required to make a policy scheme to encourage the researcher to collaborate with industry since the beginning of his/her research by making the cooperation or collaboration between them as the primary requirement for obtaining the desired incentive research. The other strategy is to enforce the pre-research on people' necessity and what the research can contribute to them.

c. Ministry of Research, Technology, and Higher Education needs to build a database in research and development fields by the agency of research and development and College to ensure the research can be the principal reference for future research and to prevent similar and double study on the same subject, thus lead to better and more synergic continuity of the research.

d. Ministry of Research, Technology, and Higher Education is required to guard the coordination between the researcher and the related sector in the transmission process of a research into an industrial product, such as the Ministry of Health, Ministry of
Industry, Ministry of Commerce, Ministry of Finance, etc.

e. The leader is advised to show real act and supportiveness towards the transmission process. The role of a leader is not only obliged to the encouragement in such a formal manner but also to actively promote the innovations by using or wearing said the products as an example to the other officials.

f. The related ministries, for example, Ministry of Commerce, Ministry of Health, Ministry of Finance and LKPP are expected to give a heartening response and supports towards the transmission process by maintaining coordination, prioritizing, and giving convenience such as certificates and promotion, distribution to Ministry of Research, Technology, and Higher Education flexibly.

2. For the Researchers

a. Researchers in both in the agency of research and development and colleges must carry out the planning and research on the market needs before starting the research to ensure that the conducted study has a contribution to the society.

b. Researchers have to broaden their networking with fellow researchers in the agency of research and development and colleges, or with the regulator of the industry to make sure they are not missing the trends in the circulation of information and technological development.

c. Researchers must be open to any collaboration with related party to ensure the more synergic, advanced, and continuous research and development.

d. Colleges necessitate industry-based learning system which is achieved through the collaboration with industry and business world that integrates the educational curriculum into the needs and the dynamics of developed technology and industry.

3. For the Industry

a. The industry is expected to be active and proactive in supporting the research and development by the agency of research and development and colleges, especially the ones which scope is core business, thus 
contributing to the circulation of the trends in the market to the researchers.

b. The industry is advised to be able to invest some of its profits in research and development that is done by the agency of research and development and colleges to fund the transmission process which will be resulted in desired products by industry.

4. Future Research

a. Future research should focus more on the interaction between stakeholders involved in collaboration especially in the commercialization phase and the market response to the circulation of bone implants

\section{Bibliography}

[1] Ansell, C., \& Gash, A. (2008). Collaborative Governance in Theory and Practice. Journal of Public Administration Research and Theory, 543-571.

[2] Leydendorff, L. (2006). The KnowledgeBased Economy And The Triple Helix Model.

www.leydesdorff.net/arist09/arist09.pdf.

[3] OECD. (2013). Triple Helix Partnership For Innovation in Bosnia And

Herzegovina.https://www.oecd.org/inves tmentcompact/Triple\%20Helix\%20Engli sh\%20Version.pdf.

[4] Wanna, J., \& O'Flynn, J. (2008). Collaborative Governance, A new era of public policy in Australia? Canberra: ANU Press. 